\title{
Enthusiasm or uncertainty: small area variations in the use of mammography services in Ontario, Canada
}

\author{
Vivek Goel, Karey Iron, J Ivan Williams
}

\begin{abstract}
Study objective-To examine the variation in mammography utilisation in relation to age group and indication across health planning regions in Ontario, Canada.

Design-This study includes all women aged 30 and over in Ontario who received a mammogram between July 1, 1990 and December 31, 1991. Data from a sample of 10000 women aged 50-69 were used to assign mammogram indication as "screening", "possible diagnostic", or "probable diagnostic" based on previous health care utilisation patterns. Age specific rates and age adjusted rates in relation to age group $(30-39,40-49,50-69$, and 70 + years) and region were derived.

Main results-Overall, 572762 women received one or more mammograms. Rates increased from 30 to 54 years and decreased thereafter. Similar variations were seen in the 40-49 and 50-69 age groups. The ranking in the area specific rates remained consistent for all ages except the 30-39 year range. In relation to indication, the largest variation across regions occurred in the screening group.

Conclusions-Mammography utilisation varies across age groups. The greatest variability is for screening, probably because of physician referral patterns, patient uptake, and perhaps access to mammography. The extent of variation was similar when compared between groups where recommendations were consistent (ages 50-59) and where they were inconsistent (ages 40-49) suggesting that perhaps enthusiasm rather than uncertainty is related to regional variation for this procedure.
\end{abstract}

( $\mathcal{F}$ Epidemiol Community Health 1977;51:378-382)

Mass screening for breast cancer using mammography has been shown to be effective in reducing breast cancer mortality in women aged 50-69 years ${ }^{12}$ and is currently recommended as part of standard primary care for this age group in Ontario, Canada. ${ }^{3}$ There is controversy, however, regarding the appropriateness of screening women aged 40-49. Some argue that, based on the evidence, mass screening does not reduce breast cancer mortality in these women. ${ }^{45}$ Others contend that the evidence does support the need for screening and physical examination for women in their 40s and that technological advances have improved the quality of mammography so that smaller tumours can be detected earlier. ${ }^{67}$

In Ontario, it is estimated that $70 \%$ of women aged 50-69 would need to undergo breast screening every two years in order to achieve a $30 \%$ reduction in breast cancer mortality. ${ }^{8}$ However, data from the 1990 Ontario health survey (OHS) showed that only $32 \%$ of women aged $40-49$ and $30 \%$ of women aged $50-69$ reported receiving a mammogram in the two years before the survey. Only $43 \%$ of women in both age groups reported ever having one. ${ }^{9}$ The similarity of the reported rates from the OHS in women aged 40-49 and 50-69 years suggests that the evidence for mammography in both age groups was regarded equally by women and/or their physicians in the early 1990s.

Like most medical services in Ontario, mammography is currently covered under the provincially managed universal health insurance plan (Ontario Health Insurance Plan-OHIP). Until 1990, only diagnostic mammography was covered in the fee schedule-screening was technically not an insured service. However, levels of mammography utilisation prevalent in the population suggest that screening was being offered through the diagnostic code. In 1990, the Ontario breast screening program (OBSP) was developed to improve the population coverage of screening mammography and to provide a means for quality assurance and program evaluation. This programme offers breast screening through clinical examination and mammography every two years to women aged 50-69. In Ontario therefore, women can receive a mammogram through their physician or self referral to the OBSP or through physician referral to an independent radiologist.

Many study methodologies and data collection strategies have been used to study mammography utilisation. Some studies use chart or radiography audits in specific medical environments, ${ }^{10} 11$ others use existing clinical databases, ${ }^{1213}$ while others utilise telephone and mail surveys ${ }^{1415}$ to assess the extent of mammography use. These studies are useful but often limited to specific populations. Population based surveys ${ }^{91617}$ and linked survey/ administrative data ${ }^{18}$ have been used to examine the individual factors affecting mammography utilisation. Survey data are beneficial because individual information can be collected that would not otherwise be available. However, the respondents may not be representative 
of the population or the results may suffer from proxy response bias and/or recall bias. ${ }^{1920}$

Small area rate variation analysis has been used to examine many medical procedures. ${ }^{212223}$ These studies provide a general description of health care delivery in a given location, are typically population based, and use local geographical areas as the unit of analysis. Explanations for observed variation may include differences in the burden of disease, sociodemographic factors affecting utilisation, supply of health care resources, inappropriate provision of medical care, physician practice style, and patient uptake practices. ${ }^{242526}$ To date, few studies of this type have examined non-surgical interventions and fewer still have focussed on a diagnostic or screening test such as mammography.

Debate has occurred on whether differences in practice patterns might be attributed to physician uncertainty about a procedure's merits or to enthusiasm for it. If uncertainty is an explanation, one would expect greater variability for procedures where there is a lack of consensus over use. Mammography utilisation in the early 1990s provides an opportunity of studying this since there was consensus over its use as a screening test in women aged 50-69 but not for those aged 40-49. There was also general consensus against its use as a screening test in women less than 40 , and limited evidence either way for women over 70 .

Although differences in mammography utilisation across urban/rural strata and across town population size using survey data have been previously demonstrated, ${ }^{131827}$ we are unaware of any population based studies that examine patterns of mammography utilisation at the small area level.

This study utilises population based administrative data to assess mammography rate variations among health planning regions in a setting with provincially funded universal health insurance. The small area analysis examines the variation in mammography utilisation across age groups and indications. We hypothesised that variations would be greater when there is uncertainty about the indication, such as in women aged 40-49 compared to those aged 50-59.

\section{Methods}

Data on all women residing in Ontario who had received at least one mammogram from July 1, 1990 to December 31, 1991 were extracted from the OHIP data files of claims submitted by physicians on a fee-for-service basis. The study period was selected to coincide with the first 18 months of operation of the OBSP. Women having mammograms were identified through billings for fee codes X184X187 (unilateral/bilateral mammogram using designated equipment and xeroradiography). The index mammogram was identified as the first mammogram claimed for an individual in the study period. Women under the age of 30 were excluded because there were relatively few mammograms recorded for them and it is likely that these would have tended to be for diagnostic purposes. Records with a missing or incorrect postal code or those with an out of province postal code were excluded from analysis.

Based on residence postal code, ${ }^{28}$ each subject was assigned to one of the 33 health planning regions in Ontario. These regions, called district health councils (DHCs), identify health care needs and coordinate the planning of health services for communities in their jurisdictional area. The DHCs range in population from 81745 to 2275771 with a median population of 171178 .

For each subject, health care utilisation files were constructed incorporating all hospital discharge records from the Canadian Institute for Health Information and physician claim records from OHIP for two years before and three years subsequent to the index mammogram.

OHIP does not distinguish screening from diagnostic mammograms in its fee schedule. A random sample of 10000 women aged 50-69 and their accompanying utilisation records was therefore extracted to estimate the variation in mammography use by indication. The utilisation files for each subject were searched for physician claims or hospitalisations records with breast disease or procedures. The index mammograms were then classified as:

1. Screening - defined as those subjects with no breast disease in the past two years based on physician claims and hospitalisation records;

2. Possible diagnostic-women who had possible breast disease based on physician billing claims for unspecific breast disease;

3. Probable diagnostic - based on physician claim coding for benign or malignant breast cancer or breast surgical procedures.

Age specific mammography rates were calculated for five year age groups from 30 years of age to 90 years and over using the 1991 Ontario census female population as the denominator. Rates were annualised for the 18 month study period by multiplying by two thirds (12 months/18 months)

Annualised age standardised mammography rates for each DHC were calculated for the entire sample and for the age groups 30-39, $40-49,50-69$, and 70 and over. Five year age ranges within these groups were used for indirect standardisation. Spearman rank correlation coefficients were calculated to examine the relationships between the ranked area specific rates across these age groups and between the different indication categories.

Standard summary measures that describe the extent of regional variation across the DHCs were calculated. ${ }^{29}$ These were: the extremal quotient which is the ratio of the highest and lowest rate; the coefficient of variation (CV) which is the ratio of the standard deviation of rates to the mean regional rate; and the systematic component of variation, which estimates the variability among regions that cannot be accounted for by chance. The adjusted likelihood $\chi^{2}$ ratio was used to test the null hypothesis that the observed regional variation was different from that expected by chance alone. Logistic regression models were 


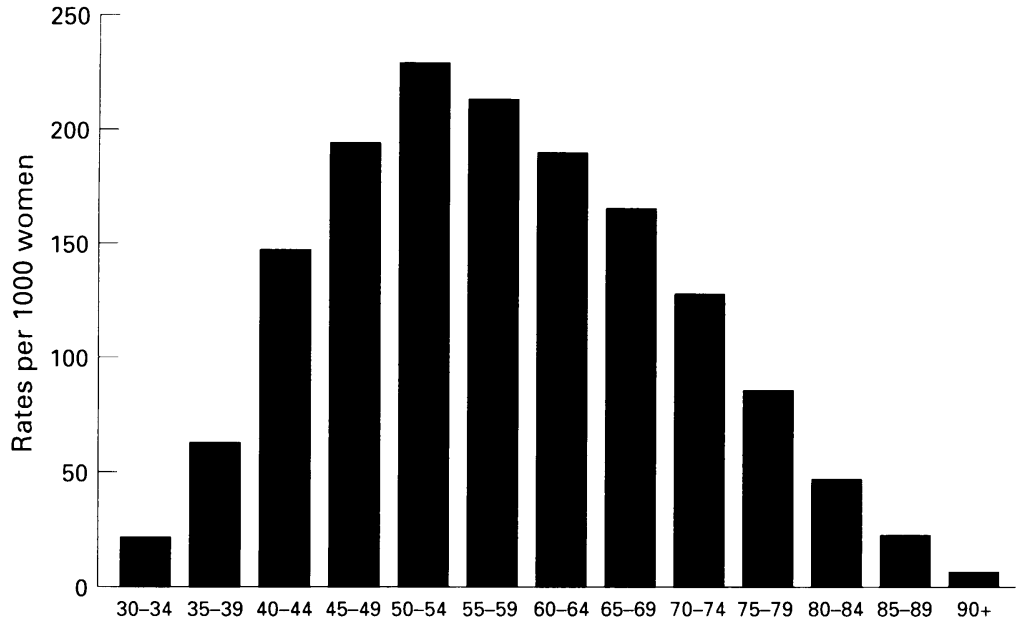

Age group

Figure 1 Age specific mammography rates per 1000 women aged 30 and over in Ontario, 1990-91.

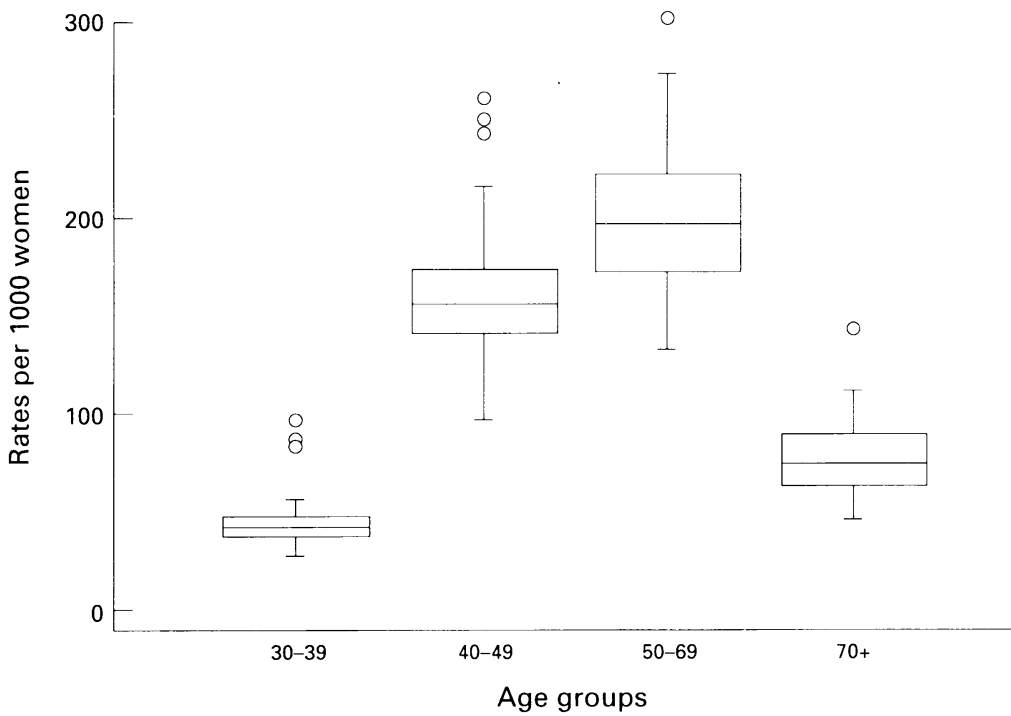

Figure 2 Distribution of age adjusted mammography rates per 1000 women across district health councils in relation to age group in Ontario, 1990-91. The boxes range from the 25 th to the 75 th centile (interquarterile range) with the line in the middle of the box representing the median or 50th centile. The lines extending from the box are defined as three halves the interquartile range. The individual points represent values for the district health councils that are considered to be outliers.

Table 1 Summary statistics for small area rate variations in the use of mammography across district health councils in relation to age group, Ontario, 1990/1991

\begin{tabular}{lllll}
\hline Age group $(y)$ & $\begin{array}{l}\text { Extremal } \\
\text { quotient }\end{array}$ & $\begin{array}{l}\text { Coefficient of } \\
\text { variation }\end{array}$ & $\begin{array}{l}\text { Systematic component } \\
\text { of variation }\end{array}$ & $\begin{array}{l}\text { Age adjusted likelihood } \\
\text { ratio } \%^{2}(d f=31)\end{array}$ \\
\hline $30-39$ & 3.51 & 30.02 & 128.66 & $2966^{*}$ \\
$40-49$ & 2.71 & 18.08 & 53.16 & $4540^{*}$ \\
$50-69$ & 2.26 & 15.58 & 40.97 & $5777^{*}$ \\
$70+$ & 3.25 & 23.17 & 80.11 & $2298^{*}$ \\
Whole cohort 30+ & 2.45 & 17.23 & 48.84 & $13564^{*}$ \\
\hline
\end{tabular}

$* \mathrm{p}<0.0001$

Table 2 Spearman rank correlation analysis across district health councils in relation to age group, Ontario, 1990/1991

\begin{tabular}{|c|c|c|c|c|}
\hline Age group (y) & $30-39$ & $y 40-49 y$ & $50-69 y$ & $70+y$ \\
\hline $30-39$ & 1.0000 & $\begin{array}{l}0.6496 \\
(p<0.0001)\end{array}$ & $\begin{array}{l}0.5949 \\
(\mathfrak{p}=0.0005)\end{array}$ & $\begin{array}{l}0.5488 \\
(p=0.0014)\end{array}$ \\
\hline $40-49$ & & $\begin{array}{l}(\mathrm{p}<0.0001) \\
1.0000\end{array}$ & $\begin{array}{l}0.9021 \\
(p<0.0001)\end{array}$ & $\begin{array}{l}0.8985 \\
(\mathrm{p}<0.0001)\end{array}$ \\
\hline $50-69$ & & & 1.0000 & $\begin{array}{l}0.9513 \\
(\mathrm{p}<0.0001)\end{array}$ \\
\hline $70+$ & & & & 1.0000 \\
\hline
\end{tabular}

used to calculate the $\chi^{2}$ value while adjusting for age differences.

Access to data was made available through research agreements with the Ontario Ministry of Health and included approvals under Ontario privacy legislation. Identifying information was removed from the records before analysis.

\section{Results}

In the 18 month study time period, 572762 women with one or more claims for mammography were identified. Residence information was available on $99 \%$. Thirteen per cent (or 377577 ) of women in Ontario aged 30 and over had at least one mammogram, annualised over the study time period. Age specific rates increased dramatically from age group 30-39 to 40-49 and continued increasing to age 54 ; thereafter, the rates decreased (fig 1).

Overall, an extremal quotient of 2.45 was found between the highest and lowest DHC rate. The distribution of the age adjusted rates across the DHCs in relation to age group is displayed in the box plots in figure 2. The interquartile range for the rates is largest in the 50-69 year group and smallest in the 30-39 year group. Table 1 shows the small area variation analysis summary measures in relation to age. The largest rate variations across DHCs occur in the youngest and the oldest age ranges. The regional variation in the age adjusted rates was statistically significant for all age groups and for the entire population aged 30 and over $(\mathrm{p}<0.0001)$.

For the age groups 40-49, 50-69, and 70 and over the ranking in the area specific rates was consistent across age groups with spearman rank correlation coefficients greater than 0.90 . The relationship between the rates for women aged 30-39 and the other age groups was less strong (table 2).

When the random sample of 10000 women aged 50-69 was stratified into specific disease states before the index mammogram $72 \%$ had no disease, $18 \%$ had possible disease, and $11 \%$ had probable disease. The variation in the age adjusted rates across DHCs was greatest for those who had a screening mammogram. There was no systematic correlation between DHCs that had high or low rates across the indications for mammography.

\section{Discussion}

This study examines the variation in utilisation rates for a screening and diagnostic test using population based data in a setting with universal health insurance. Variation in mammography utilisation exists across health planning regions and is greater than that expected by chance alone. The ranked area specific rates are consistent across most age groups. Variation in utilisation within discrete age groups is also found. The least variation is seen in the 50-69 age range, which has the highest utilisation rates and for which screening mammography is recommended. There is slightly more, but 
not much, variability in the $40-49$ year group. This suggests that instead of following the Ontario guidelines of screening women aged 5069 , some Ontario physicians may have followed American guidelines which did recommend screening younger women during this time period. ${ }^{30}$ In addition, American media may have influenced women in their 40 s to seek mammography. The data do not support the notion that controversy or uncertainty about screening in this age group significantly increased variation in use of mammography.

A multitude of factors may influence the utilisation of mammography in one region or another. Variation in the prevalence and incidence of breast disease across regions may be one influential element. Breast cancer is a major cause of mortality in women in Ontario, however the incidence does not vary significantly across the province. ${ }^{31}$ Moreover, there is no reason to expect a variable prevalence or incidence of breast disease or symptoms requiring mammography across regions. The data in relation to indication show that there is greater variability for screening mammography than for mammography for probable breast disease and this suggests that variation in prevalence or incidence in breast disease is less likely to account for the overall variability in screening. Furthermore, the age specific data show that the greatest variation occurs in groups where there is the least evidence for screening-the youngest and oldest women. The level of mammography utilisation in the 35-39 and 70-79 year old groups suggests some screening was being done in these age groups.

Access to and availability of mammography may also play a part in determining the variation. Ontario is a geographically large province with most of its 10 million residents living in the southern regions. Most of its northern area is sparsely populated with medical centres focussing on primary care. Residents in the north are often required to travel great distances to receive care requiring technologically advanced methods. As such, access to mammography may be difficult for some women in the province. In the south, some areas may have more mammography facilities per capita than others.

Patient characteristics and behaviour are important in the examination of the reasons for the variation. Utilisation of mammography is discretionary to some degree since most of the utilisation is for screening purposes. Direct payment for the procedure is not a factor for Ontario residents, as mammography is covered under the provincial health care insurance plan.

Individual factors associated with mammography use have been extensively studied. ${ }^{91718}$ The number of visits to a physician is consistently associated with mammography utilisation. There is less consistency regarding the value of the geographical area of a woman's residence for predicting mammography utilisation. However, many of the socioeconomic factors that are correlated with the use of mammography services, such as income and education, are also related to place of residence.

Resource and organisational issues have also been postulated to influence small area rates.
It is unlikely that the introduction of a fully coordinated breast screening programme (OBSP) in the province during the study period directly affected the overall screening rates. Only nine centres across the province were fully functional in the first 18 months of operation and the utilisation was not as large as expected, with only 50000 women screened, all in the 50-69 year age group..$^{32}$ Inclusion of these data would not alter our conclusions. However, the OBSP may have indirectly affected screening utilisation across areas. The programme was regionalised so that population based health promotion and education strategies and the extent of physician "buy in" to the programme were variable across the sites. Some areas may have had heightened awareness and acceptance of screening by both physicians and women, thus affecting utilisation across all age groups.

Wennberg has postulated that one explanation for variation is disagreement among the medical community regarding referral for a given procedure. ${ }^{24}$ These data suggest that variations were as great in those age groups for which there was disagreement about screening, as there was for those for whom there were clear recommendations.

Chassin suggests an enthusiasm hypothesis for explaining small area variation of carotid endarterectomy. ${ }^{33}$ Enthusiasm could influence the variation of rates through a position statement issued by a regional specialty group or through actions by a respected physician or opinion leader in the field. Physicians in some areas may have become enthusiastic about mammography as a screening tool. The similarity between levels of mammography use across age groups within regions suggests that enthusiasm of physicians in those areas for mammography may be one explanation. Other explanations for differences may be as follows: differences across regions in mammography resources, although one could argue that enthusiasm leads radiologists to purchase mammography units; differences in physician beliefs and attitudes about disease prevention, although this could result in enthusiasm; or differences between communities in such attitudes, eg among individual women, community, organisations, or media outlets.

While the current study benefits from utilising data from a specified population base it is open to the usual limitations of administrative data. While readmissions and double counting are often problematic, ${ }^{212229}$ in this study claims were matched so that only one mammogram per woman was counted.

A combination of hospital and physician claims data was used to examine regional variation across disease states before the index mammogram. The most significant breast diagnosis or procedure during the two year period was extracted. The main analysis considers total mammography utilisation because our method of distinguishing screening from diagnostic mammography was rather crude. Despite this, our observed screening level is consistent with contemporaneous self reported survey data. Furthermore, the lower variability for diagnostic mammography, which is less 
discretionary, suggests that the classification in relation to indication was reasonable.

The secondary databases that were used were developed for administrative purposes only and not research. The accuracy of the OHIP database has not been assessed for such purposes, however, we are confident that the coding is fairly reliable since the main item of analysis was a fee service code rather than a diagnostic code. Unlike the diagnostic codes, the fee service code is required for payment purposes and can be audited.

Despite the fact that mammography is covered under the provincial health insurance plan for all women in Ontario, overall utilisation was low, especially in the age group for which screening is recommended. Regional utilisation is variable across all age ranges. It is likely that the variations are due to physician referral patterns for screening, patient uptake, and, perhaps, access to the procedure. As mammography can potentially reduce the mortality of women in certain age ranges, a more integrated health promotion strategy for women, a more intensive education scheme for physicians, and an assessment of mammography supply and demand are necessary for improving access to this service.

Funding: Dr Goel is supported in part by a National Health Scholar Award from Health Canada.

1 Fletcher SW, Black W, Harris R, Rimer BK, Shapiro S Report of the international workshop on screening for breas cancer. Bethesda: National Cancer Institute 1993.

2 Miller AB, Baines CJ, To T, Wall C. Canadian national breast screening study: 2 . Breast cancer detection and death rates among women aged 50-69. Can Med Assoc $\mathcal{F}$ 1992; 147:1477-78.

3 Health Canada. The Canadian guide to clinical preventive health care: The Canadian Task Force on the Periodic Health Examination. Ottawa: Canada Communication GroupPublishing, 1994.

4 Miller AB, Baines CJ, To T, Wall C. Canadian National breast screening study: 1 . Breast cancer detection and death rates in women aged 40-49 years. Can Med Assoc death rates in women

5 Rutqvist LE, Miller AB, Andersson I, Hakama M, Hakulinen T, Sigfusson BF, Tabar L. Reduced breast-cancer mortality with mammography screening - an assessmen of currently available data. Int $\mathcal{F}$ Cancer 1990; S5:76-84

6 Clay MG, Hislop TG, Kan L, Olivotto IA, Burhenne LJW. Screening mammography in British Columbia: 19881993. Am f Surg 1993;167:490-92.

7 Moskowitz M. Guidelines for screening for breast cancer. Is a revision in order? Rad Clin North Am 1992;30:221-33.

8 The Workshop Group. Reducing deaths from breast cancer in Canada. Can Med Assoc F 1989;141:199-201.
9 Mercer SL, Goel V. Factors associated with mammography utilization: results from the Ontario health survey. Cancer Prevention and Control 1997 (in press).

10 Howe H. Repeat mammography among women over 50 years of age. Am $\mathcal{F}$ Prev Med 1992;8:182-85.

11 Nasseri K, Batani R, Bernstein S, Breslow L. Hospital information system and patterns of cancer screening. $\mathcal{F}$ Med Syst 1994;18:335-42.

12 Sienko DG, Hahn RA, Mills EM et al. Mammography use and outcomes in a community: the Greater Lansing area mammography study. Cancer 1993;71:1801-9.

13 White E, Urban N, Taylor V. Mammography utilization, public health impact and cost-effectiveness in the United public health impact and cost-effectiveness in the
States. Ann Rev Public Health 1993;14:605-33.

14 Degnan D, Harris R, Ranney J, Quade D, Earp JA, Gonzalez J. Measuring the use of mammography: two methods J. Measuring the use of mammography: two
compared. Am $\mathcal{F}$ Public Health 1992;82:1386-88.

15 Polednak AP, Lane DS, Burg MA. Mail versus telephone surveys on mammography utilization among women 50-75 years old. Med Care 1991;29:243-50.

16 Zapka JG, Stoddard AM, Costanza ME, Greene HL. Breast cancer screening by mammography: utilization and associated factors. Am $\mathcal{F}$ Public Health 1989;79:1499-1502.

$17 \mathrm{Katz}$ SJ, Hofer TP. Socioeconomic disparities in preventive care persist despite universal coverage: breast and cervical cancer screening in Ontario and the United States. $\mathscr{F A M A}$ 1994;272:530-34.

18 Potvin L, Camirand J, Beland F. Patterns of health services utilization and mammography use among women aged 50-59 years in the Quebec Medicare system. Med Care $50-59$ years in
$1995 ; 33: 515-30$

19 Mosely II RR, Wolinsky FD. The use of proxies in health surveys, substantive and policy implications. Med Care 1986;24:496-510.

20 Walter SD, Clarke EA, Hatcher J, Stitt LW. A comparison of physician and patient reports of Pap smear histories. $\mathcal{F}$ Clin Epidemiol 1988;41:401-10.

21 Hall $R$, Cohen $M$. Variations in hysterectomy rates in Ontario: does the indication matter? Can Med Assoc F 1994; 151:1713-19.

22 Ugnat AM, Naylor CD. Regionalized delivery and variable utilization of coronary artery bypass grafting in Ontario from 1981-1991. Can Med Assoc f 1994;151:575-80.

23 Iscoe NA, Goel V, Wu K, Fehringer G, Holowaty EJ, Naylor $\mathrm{CD}$. Variation in breast cancer surgery in Ontario. Can Med Assoc ₹ 1994;150:345-52.

24 Wennberg JE. Future directions for small area variations. Med Care 1993; 31:YS75-YS80.

25 Volinn E, Ciol MA, Loeser JD. Why does geographic variation in health care practices matter? (And seven question to ask in evaluating studies on geographic variation). Spine 1994;19:2095S-2100S.

26 Health Services Research Group. Small-area variations: what are they and what do they mean? Can Med Assoc $\mathcal{F}$ 1992;146:467-70.

27 Andrews HF, Kerner JF, Zauber AG, Mandelblatt J, Pittman J, Struening E. Using census and mortality data to target small areas for breast, colorectal and cervical cancer screening. Am f Public Health 1994;84:56-61.

28 Statistics Canada, Geography Division. The postal code conversion file (PCCF). January 1993.

29 Diehr P, Cain K, Connell F, Volinn E. What is too much variation? The null hypotheses in small-area analysis. vealth Services Res 1990;24:741-71.

30 Breast cancer screening guidelines agreed on by the American Medical Association and other related organizations. ican Medical Association
$\mathcal{I} A M A 1989 ; 262: 1155$

31 Marrett LD, Nishri ED, Swift MB, Walter SD, Holowaty EJ. Geographic distribution of cancer in Ontario. Atlas of cancer incidence, 1980-1991. Toronto: Ontario Cancer Treatment and Research Foundation, 1995.

32 Perrault D, Libstug A, Mercer S, Vayda E. The Ontario breast screening program: the first 18 months. Ontario Medical Review 1992:59:27-36.

33 Chassin M. Explaining geographic variations: the enthusiasm hypothesis. Med Care 1993;31:YS37-YS44. 